BOOKS

\title{
Baring the soul
}

Previously published at www.cmaj.ca

The Soul of Medicine: Tales from the Bedside

Sherwin B. Nuland

Kaplan Publishing; 2009

214 pp \$30.95

$\mathrm{T}$ his collection is arranged into a series of "tales" in which author Sherwin Nuland offers a number of perspectives on the question: "Tell me about your most memorable patient." There are 20 tales in all, arranged according to specialty, most with a commentary by the narrator, understood to be Nuland himself, who also provides a couple of tales.

The obvious question is whether the structure, with its direct reference to The Canterbury Tales, offers some advantage over, say, a simple collection of personal essays about clinical experiences. The risk of modelling the narratives after The Canterbury Tales so explicitly (even the setting is Canterbury) is that if it doesn't work convincingly — by offering the reader some particular insight, a taste of subversion or irony that serves the content - the whole endeavour can come off as, at best, a conceit. At worst, it can trivialize the story. But as an admirer of Nuland's work - especially his intrepid Maimonides and his much lauded How We Die - I entered The Soul of Medicine with an open mind about the approach.

What I didn't foresee is that constructing the stories in this way would lead to a particular prose style. Here are some samples:

"But one day the stratagem did not work, and thereon hangs the Tale."

"I have been at several autopsies where even death refuses to yield its secrets to the meticulous probing of which postmortem studies of organs, tissues and fluids consist."

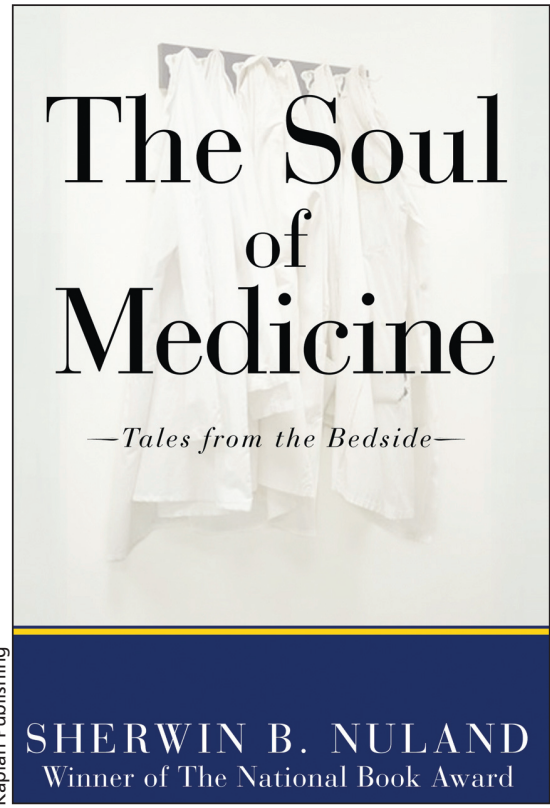

"With this long prelude involving morals on one hand and mayhem on the other ... you are, I hope, prepared to read a story like no other, which I have already claimed this Tale to be."

Plainly, this is bad writing, verbose and full of affectation, and many of the tales are similarly tainted. Instead of feeling I was being confided to by a colleague, I had a sense of being cornered by a raconteur oblivious to how often I checked my watch - and for this reason many of the stories, despite some otherwise very compelling narrative, left me unmoved. Perhaps this is the central critique of the book: Its construction entrains a certain tone, which is not only tiresome, but does an injustice to the content.

Some stories do manage to rise above these difficulties. "The Cardiologist's Tale" recounts a touching relationship between physician and patient and nicely captures the sort of emotional symbiosis that enriches both lives. As well, Nuland should be congratulated for his candour on including several tales about physician misbehaviour.
The chapter that sealed my opinion of the book was "The Medical Student's Tale," where a married man is seen in the emergency room for genital cellulitis after visiting a brothel. The medical student (accompanied by the narrator, who makes a cameo in a suspiciously large number of tales) discovers their patient, Peaches Pasqualani, has visited the whorehouse with the knowledge and the consent of his "chubby little wife." The medical student, who crows to us that he "considered the sanctity of the family my main goal in life" is openly disgusted by this man and his culture that he feels condones this sort of behaviour. The student flies into a rage, but a simple verbal humiliation of the patient isn't enough: "Slashing into Peaches' foreskin did not ameliorate my anger, nor lessen the thoughts of my wife and two babies at home. I asked for the responsibility of changing the daily dressing."

The narrative devolves from there: "Those were my favourite times of the day. Morning and evening, I would vengefully march into the four-bed room where Peaches was boarded, and he'd turn white on me appearing there."

I was revolted merely by having to transcribe that passage, not only because this is sadism expressing itself through, and corrupting, the medical act, but because the story is related more than 40 years after it occurred without evidence that the perpetrator has in the interim acquired any self-awareness of what he has done. I could find no irony here, only gloating. Unlike other tales where Nuland editorializes on those who have committed misdeeds (seven pages of rebuttal, in one case), no comment is offered here.

I trust many in Nuland's medical readership can make up their own minds about right and wrong, but given the sort of misadventures doctors have historically found themselves caught up in - 


\section{POEM}

\section{Postscript}

All afternoon she lay, silent and quiet,

her eyes shut.

By evening the visitors started to leave,

And I was on the brink of going too,

But I did return, and whispered into her ear,

not expecting a reply

A tender farewell

"Good-night, my darling. We will see you tomorrow"

And she replied,

"Good-night my darling. I hope to see you tomorrow, too"

I cannot forget those words

Whispered in that voice I loved so much

Which meant she was still alive, and hoping.

But alas, she went into a coma soon after

And there was not to be another tomorrow for her

Nor would I see her look for me then,

Nor ever again, in this life.

\section{Frank Irwin Jackson MD}

Radiologist

Edmonton, Alta.

often in the name of the righteousness - I wanted a word of comment from Nuland about this physician's motivation and felt the omission deeply. But maybe I am being too harsh. Maybe this wasn't an act of medical torture after all, just another tale. Still, I like to think that even in Canterbury they can tell the difference between the board certified and the water board certified.

Let's end with the summation of wisdom from "The Medical Student's Tale." "Three days later, the dressings were discontinued and I lost my status as an avenging angel. But it was a great ride while it lasted."

Actually, maybe it wasn't such a great ride. If this is the soul of medicine, let me be bereft.

\section{Liam Durcan MD}

Neurologist

Montreal Neurological Hospital

Montréal, Que.

Dr. Durcan is the author of two books of fiction, Garcia's Heart (2007) and A Short Journey by Car (2004). He is currently completing his next novel.

This poem is dedicated to the memory of the author's wife, Leoné Jackson MD. The author's poetry is gathered into three volumes including, most recently, Leoné, Sagas of the Red Canary, and other poems (2009).

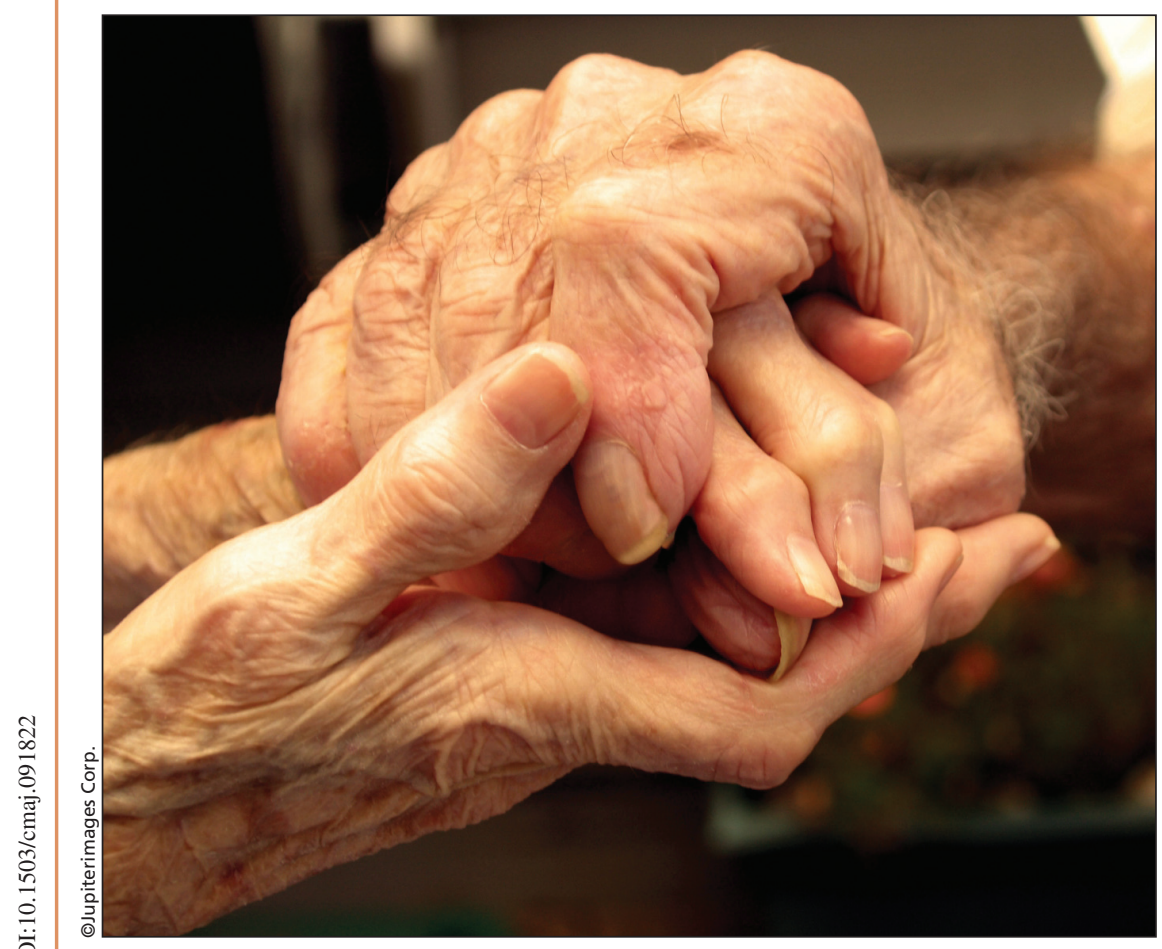

